\title{
Epidemiology of feline hemoplasmosis in the population of domestic cats in Istanbul|1)
}

\author{
BARAN CELIK, LORA KOENHEMSI*, BANU DOKUZEYLUL*, \\ BEREN BAŞARAN KAHRAMAN, BELGI DIREN SIĞIRCI, SERKAN IKIZ, \\ SEYYAL AK, ARZU FUNDA BAGCIGIL
}

\begin{abstract}
Department of Microbiology, *Department of Internal Medicine, Faculty of Veterinary Medicine,
\end{abstract} Istanbul University-Cerrahpasa, 34320 Istanbul, Turkey

Çelik B., Koenhemsi L., Dokuzeylul B., Basaran Kahraman B., Diren Sigirci B., Ikiz S., Ak S., Bagcigil A. F. Epidemiology of feline hemoplasmosis in the population of domestic cats in Istanbul

\section{Summary}

The aim of this study was to determine the prevalence of hemoplasma species in cats by real-time PCR and to determine the distribution of the species. Furthermore, it was aimed to evaluate factors that are thought to be important in the epidemiology of the disease in cats statistically. For this purpose, blood samples from 246 cats were examined for Candidatus Mycoplasma haemominitum (CMhm), Mycoplasma haemofelis (Mhf) and Candidatus Mycoplasma turicensis $(C M t)$ by real-time PCR. CMhm was detected in $20(8.13 \%)$, CMt was detected in $3(1.22 \%)$, and $M h f$ was found in $2(0.81 \%)$ of 246 cats. At least one of the hemoplasma species was detected in $21(8.54 \%)$ of 246 cats, and two different hemoplasma species were detected in $4(19.05 \%)$ of 21 cats diagnosed with hemoplasma. The relationship between PCR positivity, the contact of cats with other cats $(p=0.02)$ and the detection of the intraoral wound $(p=0.001)$ was found to be statistically significant. The statistical significance of contact with other cats in the formation of the disease was revealed. The strong relationship between the presence of intraoral lesions and hemoplasma infection was revealed for the first time. Studies involving epidemiological data and their relationship with clinical findings should be continued.

Keywords: feline hemoplasma; prevalence, real-time PCR, risk factors

Hemoplasmas are organisms attached to the surface of erythrocytes of various mammalians, in which they cause anemia. The species described in cats are as follows: Mycoplasma haemofelis (Mhf), Candidatus Mycoplasma haemominitum $(C M h m)$, Candidatus Mycoplasma turicensis $(C M t)$, and Candidatus Mycoplasma haematoparvum. Mhf is the most pathogenic species in cats, most frequently responsible for clinical cases $(4,6,20,21)$. In Turkey there are few studies on hemoplasma infections in cats. The first hemotropic mycoplasma was reported in a cat in Istanbul in 1993 (25). A number of subsequent studies were limited to case reports and reports based on a microscopic examination $(1,3)$. The diagnosis of $C M h$ in a cat using molecular methods was reported for the first time in 2008 (27). In Turkey, the first study on the presence of the agent at the molecular level and clinical findings was carried out in 2009 , and the

1) This study was supported by the Scientific Research Project Coordination Unit of Istanbul University-Cerrahpasa (Project code: TSA-2017-25305). The authors would like to thank Dr. Severine Tasker from Bristol Veterinary School, University of Bristol, for the positive controls. prevalence of the disease was found to be $18.9 \%$ (26). Aslan et al. (4) detected Mhf infection in a cat by PCR and electron microscope imaging. In the most recent study, hemoplasma species were examined using PCR and RFLP methods in blood samples obtained from 384 owned cats, and at least one mycoplasma species was detected in $19.3 \%$ of the cats. The prevalence of $M h f$, $C M h m$, and $C M t$ was reported to be $9.9 \%, 17.7 \%$, and $0.8 \%$, respectively (9).

Although the routes of transmission of hemoplasmas are unknown, it is thought that fleas play a role in it $(24,28)$. When the risk factors for the transmission of the disease in cats were examined, the incidence of the agent was reported to be higher in older cats usually contacting the outdoors $(13,22,24)$ and adult male stray cats $(11,24,28)$. Furthermore, it is reported that the presence of viral diseases causing immunosuppression, such as FIV and FeLV, is the most important predisposing factor for the development of the disease $(11,13,18,21,24)$.

This study's aim was to determine the presence of hemoplasma species in cats using real-time PCR and 
determine the species distribution. In addition to determining the prevalence rate, the aim was to statistically evaluate the clinical signs and demographic characteristics, such as age, breed, sex, and living conditions, which are important in the formation of the disease, and thus to obtain information about the epidemiology of the disease.

\section{Material and methods}

Blood samples were taken from cats brought to the Internal Medicine Clinic of the Faculty of Veterinary Medicine for various reasons. All clinical findings, such

Tab. 1. Sequences and annealing temperatures of the primers used in real-time PCR

\begin{tabular}{|c|c|c|c|}
\hline Species & Temperature & & Sequence \\
\hline \multirow{3}{*}{ Mhf } & \multirow{3}{*}{$60^{\circ} \mathrm{C}$} & forward & CGG CCA AGG TTA GTG GCA AAC GG \\
\hline & & reverse & TCC CTCA GCG CCC GAA GGC T \\
\hline & & probe & FAM ACA TGC CCC TCT GTG GGG GAT AGC CGC TTG TAMRA \\
\hline \multirow{3}{*}{ CMhm } & \multirow{3}{*}{$50^{\circ} \mathrm{C}$} & forward & ACG AAA GTC TGA TGG AGCA ATA \\
\hline & & reverse & ACG CCC AAT AAA TCC GRA TAA T \\
\hline & & probe & JOE AGC TTG ATA GGA AAT GAT TAA GCC TTG AA TAMRA \\
\hline \multirow{3}{*}{ CMt } & \multirow{3}{*}{$52^{\circ} \mathrm{C}$} & forward & GAA GGC CAG ACA GGT CGT AAA G \\
\hline & & reverse & CTG GCA CAT AGT TWG CTG TCA CTT A \\
\hline & & probe & FAM AAA TTT GAT GGT ACC CTC TGA MGB \\
\hline
\end{tabular}
as anemia, anorexia, fever, weight loss, jaundice, hypoglycemia, splenomegaly, paleness of the mucosa, and depression, were recorded for statistical analysis. According to the results of a study conducted in Turkey, the prevalence of the disease was found to be $19 \%$. In this study, the blood samples of 246 cats were examined, assuming the estimated prevalence of the disease to be $20 \%$ at a $95 \%$ confidence level and 5\% absolute sensitivity.

Before sample collection, information on cats was recorded, such as age, breed, sex, external parasite control, viral diseases that might cause anemia, general health status, the reason for admission to the clinic, the form of breeding (living at home, outdoors, with more than one cat, etc.), and neutering status. When some information could not be obtained for various reasons, statistical analyses were based on the data collected. The blood samples taken with EDTA anticoagulant tubes were sent to the laboratory of the Department of Microbiology within half an hour and stored at $-20^{\circ} \mathrm{C}$ until being examined by PCR $(12,28)$.

Complete blood counts (CBC) were analyzed using the BC-2800 Vet (Mindray, Shenzen, China) hematology analyzer. The FIV Ab/FeLV Ag Anigen test (Korea) was performed following the manufacturer's instructions. As a result of the $\mathrm{CBC}$ from blood samples, hematocrit values less than 25 were considered anemic (15).

DNA was extracted from $200 \mu$ l EDTA whole blood using the QIAamp DNA Blood Mini Kit (Quiagen, Hilden, Germany), according to the manufacturer's instructions, and the extracted DNA was stored at $-20^{\circ} \mathrm{C}$. Before investigating the samples by real-time PCR, all DNA samples were examined using the conventional PCR for the presence of glyceraldehyde-3-phosphate dehydrogenase (GAPDH) gene to detect PCR inhibitors in the samples and to determine whether the extraction had been performed properly. For this purpose, $25 \mu 1$ volume of PCR mixture was prepared to contained $1 \mu \mathrm{DNA}, 0.5 \mu \mathrm{M}$ of each primer (GAPDH-F CCTTCATTGACCTCAACTACAT and GAPDH-R CCAAAGTTGTCATGGATGACC), $12.5 \mu 1$ PCR master mix (PCR master mix K0171, Thermo Scientific, Waltham, MA, USA), and $10.5 \mu 1$ distilled water. The prepared mixtures were subjected to pre-denaturation at $94^{\circ} \mathrm{C}$ for $5 \mathrm{~min}$ utes in the PCR device, followed by synthesis at $94^{\circ} \mathrm{C}$ for 30 seconds, at $52^{\circ} \mathrm{C}$ for 1 minute and at $72^{\circ} \mathrm{C}$ for 1 minute with 40 cycles, and the final elongation at $72^{\circ} \mathrm{C}$ for 5 minutes. The products were run on a $1.5 \%$ agarose gel. The 400 -bp

long bands were evaluated as positive, and these samples were examined by real-time PCR $(2,8)$.

Blood samples were examined by real-time PCR according to the method described by Duarte et al. (11) to detect three different hemoplasma species. The PCR mixture contained $4 \mu 12 \times$ LC TaqMan master mix, $0.5 \mu 1$ of each primer $(10 \mathrm{pmol})$ and probe, $5 \mu \mathrm{l}$ template DNA and $9.5 \mu \mathrm{l}$ distilled water, with a volume of $20 \mu 1$. The PCR device (Light Cycler 2.0, Roche, Basel, Swiss) was programmed to pre-steps at $50^{\circ} \mathrm{C}$ for 2 minutes and at $95^{\circ} \mathrm{C}$ for 10 minutes, and then 50 cycles at $95^{\circ} \mathrm{C}$ for 10 seconds and $50-60^{\circ} \mathrm{C}$ for 1 minute and $72^{\circ} \mathrm{C}$ for a 1 -second synthesis stage and $40^{\circ} \mathrm{C}$ for 30 seconds for cooling (11). The sequences and annealing temperatures of the primers are presented in Table 1. $M h f, C M h m$, and CMt DNA kindly provided by Dr. Severine Tasker from the Bristol Veterinary School, University of Bristol, was used as positive controls in the study.

According to the real-time PCR results, the cats were defined as hemoplasma-infected. The categorical variables (sex, species, hemoplasma coinfection, FIV and FeLV infection, contact with the outside, the place of care, etc.) were analyzed by Fisher's exact test (if the smallest theoretical frequency $<5$ ) or chi-square test (if the smallest theoretical frequency $>5$ ). A P-value $\leq 0.05$ was considered to be statistically significant $(12,16)$.

\section{Results and discussion}

According to the data collected, it was found that there were 133 male cats and 106 female cats, 77 spayed cats, 124 unspayed cats, 189 cats were over the age of 1 , and 54 cats were below the age of 1 . Two cats were Ankara cats, 13 cats were Persian cats, one cat was Scottish fold, five cats were Siamese cats, and the remaining cats were of a mixed breed. It was reported that the regular external parasite control of 96 cats was performed. However, no parasite control program was applied for 127 cats. One hundred eighty cats had a living condition at home only, while 40 cats had contact with the outside. Forty-six cats had varying degrees of anemia, and 198 cats did not have anemia.

As a result of the PCR performed after the extraction of 246 blood samples, a 400-bp long band was detected in all samples. Thus it was determined that there was no PCR inhibitor in the samples, and the 
extraction of DNA from them was performed appropriately. According to real-time PCR results, $C M h m$ was detected in $20(8.13 \%), C M t$ was detected in 3 $(1.22 \%)$, and $M h f$ was detected in $2(0.81 \%)$ of 246 cats. At least one of the hemoplasma species was detected in $21(8.54 \%)$ of a total of 246 cats. Both Mhf and $C M h m$ were detected in two cats, both $C M t$ and $\mathrm{CMhm}$ were detected in two cats, and two different hemoplasma species were detected in $4(19.05 \%)$ of the 21 cats diagnosed with hemoplasma.

According to the statistical analysis, the relationship between PCR positivity and age $(\mathrm{P}=0.36)$, sex $(\mathrm{P}=0.17)$, breed $(\mathrm{P}=0.83)$, the presence of anemia $(P=0.54)$, the presence of a viral disease $(P=0.45)$, the lack of parasite control $(\mathrm{P}=0.45)$, the detection of icterus $(\mathrm{P}=0.75)$, and contact of cats with the outside $(\mathrm{P}=0.058)$ was not found to be statistically significant. Nevertheless, the relationship between PCR positivity and the contact of cats with other cats $(\mathrm{P}=0.02)$ was found to be statistically significant. Moreover, the relationship between the detection of an intraoral wound and the detection of an agent by PCR was found to be statistically very significant $(\mathrm{P}=0.0001)$ (Tab. 2$)$.

Hemoplasma infections in cats can be observed in various forms ranging from severe anemia to chronic infections without clinical symptoms. In acutely infected animals, anemia ranging from a mild to severe form that may cause death, and anorexia, fever, weight loss, jaundice, and hypoglycemia may be observed depending on the infected mycoplasma species $(5,7,10,19$, 21, 24). Mhf and Cmt can be associated with anemia, and $M h f$ is the most pathogenic and common species responsible for clinical signs. $C M h m$ usually causes a few clinical signs $(11,12,20,24,28)$. The number of molecular studies on the presence and distribution of hemoplasma species in cats has increased, especially in the last decade. While CMhm was detected in $11.2 \%$ of cats in England, $M h f$ and $C M t$ were detected in $2.8 \%$ and $1.7 \%$, respectively (20). Maher et al. (16) determined the prevalence in Greece to be $20.6 \%$. The researchers found that seven cats were infected only with $M h f$, ten cats were infected only with CMhm, and three cats were co-infected with $M h f$ and CMhm. Nibblett et al. (19) found the prevalence of subclinical hemoplasma infection to be $8 \%$. In two different studies carried out in Portugal it was revealed that the prevalence of hemoplasma was $27.1 \%$ (11) and $43.43 \%$ (18). In Denmark it was reported that the prevalence of $C M h m$ was $14.9 \%$, and the prevalence of $M h f$ was $1.5 \%$ in cats (22). The prevalence of hemoplasma was reported to be $17.7 \%$ (13) in Japan, $13.8 \%$ (2) and $25.8 \%$ (17) in Brazil, 15.1\% (28) in Chile, 13.2\% (21) and $18.9 \%$ (12) in Northern Italy, $10.6 \%$ (10) in Spain, and $17.2 \%$ (23) in Serbia. In most of the studies, it was reported that the most frequently isolated species was $C M h m$, which was usually followed by $M h f$. Moreover, $C M t$ infection was observed as a coinfection, especially with $C M h m(2,10,11,12,17,18,20,21,28)$. In the
Tab. 2. Sample characteristics and statistical analysis of the sampled cats

\begin{tabular}{|c|c|c|c|c|}
\hline \multicolumn{2}{|c|}{ Variable (n) } & PCR (-) & PCR (+) & P-value \\
\hline \multirow{2}{*}{ Age } & $<1(54)$ & 51 & 3 & \multirow{2}{*}{0.36} \\
\hline & $\geq 1$ (189) & 171 & 18 & \\
\hline \multirow{2}{*}{ Sex } & Female (106) & 100 & 6 & \multirow{2}{*}{0.17} \\
\hline & Male (133) & 119 & 14 & \\
\hline \multirow{2}{*}{ Breed } & Non-pedigree (220) & 202 & 18 & \multirow{2}{*}{0.83} \\
\hline & Pedigree (21) & 19 & 2 & \\
\hline \multirow{2}{*}{ Blood counts } & Anemic (46) & 41 & 5 & \multirow{2}{*}{0.54} \\
\hline & Normal values (198) & 182 & 16 & \\
\hline \multirow{2}{*}{ Viral diseases } & Positive (96) & 85 & 11 & \multirow{2}{*}{0.45} \\
\hline & Negative (2) & 2 & 0 & \\
\hline \multirow{3}{*}{ Parasite treatment } & External/internal (116) & 105 & 11 & \multirow{3}{*}{0.45} \\
\hline & Internal (20) & 19 & 1 & \\
\hline & None (96) & 86 & 10 & \\
\hline \multirow{3}{*}{ Fever } & High (20) & 16 & 4 & \multirow{3}{*}{0.13} \\
\hline & Normal (219) & 202 & 17 & \\
\hline & Low (3) & 3 & 0 & \\
\hline \multirow{2}{*}{ Icterus } & Positive (28) & 26 & 2 & \multirow{2}{*}{0.75} \\
\hline & Negative (214) & 195 & 19 & \\
\hline \multirow{2}{*}{$\begin{array}{l}\text { Contact with other } \\
\text { animals }\end{array}$} & Yes (56) & 47 & 9 & \multirow{2}{*}{$0.02^{*}$} \\
\hline & No (160) & 150 & 10 & \\
\hline \multirow{2}{*}{ Living conditions } & Indoor (180) & 166 & 14 & \multirow{2}{*}{0.058} \\
\hline & Outdoor (40) & 33 & 7 & \\
\hline \multirow{2}{*}{ Spayed/neutered } & No (77) & 73 & 4 & \multirow{2}{*}{0.19} \\
\hline & Yes (124) & 111 & 13 & \\
\hline \multirow{2}{*}{ Oral lesions } & Yes (5) & 0 & 5 & \multirow{2}{*}{$0.0001^{*}$} \\
\hline & No (241) & 225 & 16 & \\
\hline
\end{tabular}

Explanations: significant associations are shown with *

first study conducted at the molecular level in Turkey, the prevalence of the disease was found to be $18.9 \%$ (26). Most recently, Çetinkaya et al. (9) investigated hemoplasma species using PCR and RFLP methods from the blood samples of 384 owned cats. As a result of the study, the researchers detected at least one of the Mycoplasma species in $19.3 \%$ of the cats. They found the prevalence of $M h f, C M h m$, and CMt to be $9.9 \%, 17.7 \%$, and $0.8 \%$, respectively. At least one of the hemoplasma species was detected in $21(8.54 \%)$ of the 246 cats examined in this study. When the species distribution was examined, it was observed that the most frequently isolated species was $C M h m(8.13 \%)$, similar to other studies. The results of the studies on the distribution of hemoplasma species vary depending on many factors, including the clinical status of the animals examined, blood parameters, the season of sample collection, living conditions of animals, and the laboratory techniques used. Since no epidemiological data on the sampled cats were available in the most recent study in Turkey, it was not possible to compare the results of the studies. Cetinkaya et al. (9) carried out 
the most comprehensive molecular study in Istanbul in 2016, and the prevalence values were observed to be lower in that study. It is considered that the difference in the prevalence values was caused by the general health status and living conditions of the cats examined, and the use of different molecular diagnostic methods in studies as the most important factor.

Many studies have found a relationship between viral diseases such as FIV, FeVL causing immunosuppression, and the high prevalence of hemoplasma $(11-14,18,21,23)$. In a study carried out on cats with anemia, FIV was detected in 2 of 39 cats when they were classified according to infectious causes (15). In this study, cats with the suspected viral disease were examined for FIV, FIP, and FeLV using rapid test kits. At least one of these viral diseases was detected in 11 of the cats diagnosed with hemoplasma. However, this relationship was not statistically significant $(\mathrm{P}=0.45)$.

When the clinical findings of cats with hemoplasma species were examined, it was observed that these cats frequently had intraoral wounds, according to the statistical analysis performed after re-evaluating all data of the cats examined. Although they were not taken as criteria while planning the study, the relationship between the formation of an intraoral wound and PCR positivity was found to be very significant. Despite the relatively small number of oral lesions reported, we believe that the correlation, which was notified for the first time, is important and should be examined in more detail concerning any significant biological effect for a further understanding of the epidemiology and pathogenesis of feline hemoplasma infections.

When the risk factors for the formation of the disease in cats were examined, they were more frequently detected in old cats having contact with the outside $(10,13,14,16,21-24)$. In particular, the fact that free-roaming cats are more likely to have contact with cats infected with hemoplasma due to their aggressive behaviors may lead to a higher rate of detecting hemoplasma species in male cats $(11,14,24)$. Makino et al. (17) reported that male cats were at a higher risk of being infected with hemoplasma infections. Vergara et al. (28) reported that $67.2 \%$ of the cats with at least one of the hemoplasma species were male cats, and $53.4 \%$ of them were cats having contact with the outside. Duarte et al. (11) reported that hemoplasma species were more frequently detected, especially in older or very young cats, although no statistically significant difference between them was found. Some researchers did not find a statistical relationship between the presence of hemoplasma and the criteria, such as sex, breed, fertility status, age, living conditions, and anemia $(18,19)$. In this study, no statistically significant relationship was found between age, sex, breed, and sexual status in terms of the incidence of hemoplasma species. However, while 180 of the cats were kept only at home, 40 of them had access to the outside, although they were cared for in the garden, at work or at home with contact with the outside. It was observed that seven of the cats diagnosed with hemoplasma had contact with the outside $(\mathrm{P}=0.058)$, and nine of the cats detected to be positive by PCR were in contact with other cats. As a result of the statistical analysis, contact with other cats $(\mathrm{P}=0.02)$ was a significant risk factor. This is not surprising since cats are social animals and often have a habit of licking each other. Stray cats constitute a significant population in Turkey. The results of the study indicate that cats in contact with others are at a high risk for hemoplasma infections.

Feline hemoplasmosis in cats can be observed in various forms ranging from severe anemia to chronic infections without clinical symptoms. Although hemolytic anemia usually emerges as a result of experimental studies carried out with $M h f$, no clear relationship has been found between the agent and anemia in the studies on the prevalence of infections occurring under natural conditions. The reason for this may be the investigation of different cat populations in the studies and the acute or chronic phase of the disease $(12,24)$. Korman et al. (15) reported that 77 of 348 cats with anemia were investigated for the presence of hemoplasma, and the ratio was found to be $7.8 \%(6 / 77)$. While $C M h m$ was detected in three of these cats, Mhf was detected in two of them, and both agents were detected in one of them. Ural et al. (26) reported that the prevalence of hemoplasma was higher in cats with clinical findings. $\mathrm{CMhm}$ was detected in $30.4 \%$ of cats with anemia, although it was not statistically significant. Other researchers have reported the lack of association between hemoplasma PCR-positive status and anemia $(6,12)$. Ravagnan et al. (21) detected $C M h m$ more frequently in cats with anemia. However, the rate of detection of $M h f$ in cats with anemia was found to be statistically significant compared to healthy cats. Cats are not capable of eliminating hemoplasma species and remain carriers. However, they exhibit clinical findings only in the first stage of the disease. Therefore, the common interpretation in most of the studies is that association with clinical findings could not be found due to the inability to determine the cats' stage of the disease. The results of our study also support this hypothesis. Anemia was observed in $46(18.7 \%)$ of the cats examined, of which only five were positive for hemoplasma. Three cats presented positivity for $C M h m$, one for $C m t$, and the last one showed co-positivity for $M h f$ and $C M h m$. However, no statistically significant relationship was found between hemoplasma positivity and the presence of varying degrees of anemia $(\mathrm{P}=0.54)$.

In this study, the current prevalence of hemoplasma in cats was found to be $8.5 \%$. Furthermore, some physiological, pathological, and behavioral variables that are thought to play a role in the formation of the disease were statistically analyzed, and the relationship between PCR positivity and the contact with other cats $(\mathrm{P}=0.02)$ was found to be statistically significant. Cats are animals that are in very close physical contact when 
they accept each other socially. They sometimes get in intense contact with each other aggressively while hunting, playing games, protecting the territory, or being angry. For these reasons, when the habitual behaviors of cats are considered, limiting these factors is the most important measure to be taken for the control of hemoplasma infections in cats. In this study, the strong relationship between the presence of intraoral lesions, one of the symptoms of many diseases in cats, and hemoplasma infection was revealed for the first time. Although there is a need for more detailed studies on the subject, it is thought that this result may help clinicians to consider hemoplasma infections in the differential diagnosis.

\section{References}

1.Akkan H. A., Karaca M., Tütüncü M., Özdal N., Yüksek N., A ğaoğlu Z., Değer S.: Haemobartonellosis in Van cats. Turkish J. Vet. Anim. Sci. 2005, 29, 709-712.

2. Aquino L. C., Hicks C. A. E., Scalon M. C., Lima M. G. da M., Lemos M. dos S., Paludo G. R., Helps C. R., Tasker S.: Prevalence and phylogenetic analysis of haemoplasmas from cats infected with multiple species. J. Microbiol. Methods 2014, 107, 189-196

3. Aslan Ö., İça A., Çam Y., Kibar M.: Kayseri'de Bir Kedide Haemobartonellozis Olgusu. Erciyes Üniversitesi Vet. Fakültesi Derg. 2010, 7, 131-135.

4. Aslan Ö., Karaca Bekdİk İ., Ilgar E. G.: Bir kedide Mycoplasma haemofelis enfeksiyonu ve etkenin taramalı elektron mikroskopi ile görüntülenmesi. Kafkas Univ. Vet. Fak. Derg. 2015, 21, 131-134.

5. Barker E. N., Tasker S., Day M. J., Warman S. M., Woolley K., Birtles R., Georges K. C., Ezeokoli C. D., Newaj-Fyzul A., Campbell M. D.: Development and use of real-time PCR to detect and quantify Mycoplasma haemocanis and "Candidatus Mycoplasma haematoparvum" in dogs. Vet. Microbiol. 2010, 140, 167-170.

6. Bauer N., Balzer H. J., Thüre S., Moritz A.: Prevalence of feline haemotropic mycoplasmas in convenience samples of cats in Germany. J. Feline Med. Surg. 2008, 10, 252-258

7.Biondo A. W., Santos A. P. dos, Guimarães A. M. S., Vieira R. F. da C., Vidotto O., Macieira D. de B., Almosny N. R. P., Molento M. B., Timenetsky J., Morais H. A. de: A review of the occurrence of hemoplasmas (hemotrophic mycoplasmas) in Brazil. Rev. Bras. Parasitol. Veterinária 2009, 18, 1-7.

8. Birkenheuer A. J., Levy M. G., Breitschwerdt E. B.: Development and evaluation of a seminested PCR for detection and differentiation of Babesia gibsoni (Asian genotype) and B. canis DNA in canine blood samples. J. Clin. Microbiol. 2003, 41, 4172-4177

9. Cetinkaya $H$., Haktanir D., Arun S., Vurusaner $C$. Molecular detection and prevalence of feline hemotropic mycoplasmas in Istanbul, Turkey. Acta Parasitol. 2016, 61, 165-171.

10.Díaz-Regañón D., Villaescusa A., Ayllón T., Rodríguez-Franco F., GarcíaSancho M., Agulla B., Sainz Á.: Epidemiological study of hemotropic mycoplasmas (hemoplasmas) in cats from central Spain. Parasit. Vectors. 2018, 11, 140 .

11. Duarte A., Marques V., Correia J. H. D., Neto I., Bráz B. S., Rodrigues C., Martins T., Rosado R., Ferreira J. P., Santos-Reis M.: Molecular detection of haemotropic Mycoplasma species in urban and rural cats from Portugal. J. Feline Med. Surg. 2015, 17, 516-522.

12. Gentilini F., Novacco M., Turba M. E., Willi B., Bacci M. L., HofmannLehmann R.: Use of combined conventional and real-time PCR to determine the epidemiology of feline haemoplasma infections in northern Italy. J. Feline Med. Surg. 2009, 11, 277-285.

13. Inokuma H., Taroura S., Okuda M., Hisasue M., Itamoto K., Une S., Nakaichi M., Taura Y.: Molecular Survey of Mycoplasma haemofelis and 'Candidatus Mycoplasma haemominutum' Infection in cats in Yamaguchi and surrounding areas. J. Vet. Med. Sci. 2004, 66, 1017-1020.

14. Jenkins K. S., Dittmer K. E., Marshall J. C., Tasker S.: Prevalence and risk factor analysis of feline haemoplasma infection in New Zealand domestic cats using a real-time PCR assay. J. Feline Med. Surg. 2013, 15, 1063-1069.

15. Korman R. M., Hetzel N., Knowles T. G., Harvey A. M., Tasker S.: A retrospective study of 180 anaemic cats: Features, aetiologies and survival data. J. Feline Med. Surg. 2013, 15, 81-90.

16. Maher I. E., Tasker S., Polizopoulou Z., Dasopoulou A., Egan K., Helps C. R., Papasouliotis $K$.: Polymerase chain reaction survey of feline haemoplasma infections in Greece. J. Feline Med. Surg. 2010, 12, 601-605.
17. Makino H., De Paula D. A. J., Sousa V. R. F., Mendonça A. J., Dutra V., Nakazato L., Do Bom Parto Ferreira De Almeida A.: Natural hemoplasma infection of cats in Cuiaba, Mato Grosso, Brazil. Semin. Agrar. 2018, 39, 875-880

18. Martinez-Díaz V. L., Silvestre-Ferreira A. C., Vilhena H., Pastor J., Francino O., Altet L.: Prevalence and co-infection of haemotropic mycoplasmas in Portuguese cats by real-time polymerase chain reaction. J. Feline Med. Surg. 2013, 15, 879-885.

19. Nibblett B. M. D., Waldner C., Taylor S. M., Jackson M. L., Knorr L. M., Snead E. $C$.: Hemotropic mycoplasma prevalence in shelter and client-owned cats in Saskatchewan and a comparison of polymerase chain reaction (PCR) - Results from two independent laboratories. Can. J. Vet. Res. 2010, 74, 91-96.

20. Peters I. R., Helps C. R., Willi B., Hofmann-Lehmann R., Tasker S.: The prevalence of three species of feline haemoplasmas in samples submitted to a diagnostics service as determined by three novel real-time duplex PCR assays. Vet. Microbiol. 2008, 126, 142-150.

21. Ravagnan S., Carli E., Piseddu E., Da Rold G., Porcellato E., Zanardello C., Carminato A., Vascellari M., Capelli G.: Prevalence and molecular characterization of canine and feline hemotropic mycoplasmas (hemoplasmas) in northern Italy. Parasit. Vectors. 2017, 10, 132

22. Rosenqvist M. B., Meilstrup A. K. H., Larsen J., Olsen J. E., Jensen A. L., Thomsen L. E.: Prevalence of feline haemoplasma in cats in Denmark. Acta Vet. Scand. 2016, 58, 78 .

23. Sarvani E., Tasker S., Kovac'ević Filipović M., Francuski Andrić J., Andrić N., Aquino L., English S., Attipa C., Leutenegger C. M., Helps C. R., Papasouliotis $K$.: Prevalence and risk factor analysis for feline haemoplasmas in cats from Northern Serbia, with molecular subtyping of feline immunodeficiency virus. J. Feline Med. Surg. Open Reports. 2018, 4.

24. Tasker $S$. Haemotropic mycoplasmas: what's their real significance in cats? J. Feline Med. Surg. 2010, 12, 369-381.

25. Tüzer E., Göksu K., Bilal T., Yesildere T.: A case of haemobartonellosis in a cat in Istanbul. J. Protozool. Res. 1993, 3, 69-70.

26. Ural K., Kurtdede A., Ulutas B.: Prevalence of haemoplasma infection in pet cats from 4 different provinces in Turkey. Rev. Med. Vet. 2009, 160, 226-230.

27. Ural K., Suer C., Vatansever Z., Kar S., Eker K., Cingi C. C.: Candidatus Mycoplasma Haemominutum" infection in a cat in Antalya. Frrat Univ. J. Heal. Sci. Vet. 2008, 22, 27-30.

28. Vergara R. W., Galleguillos F. M., Jaramillo M. G., Almosny N. R. P., Martínez P. A., Behne P. G., Acosta-Jamett G., Müller A.: Prevalence, risk factor analysis, and hematological findings of hemoplasma infection in domestic cats from Valdivia, Southern Chile. Comp. Immunol. Microbiol. Infect. Dis. 2016, 46, 20-26.

Correspoding author: Baran Celik, DVM, PhD, Istanbul UniversityCerrahpasa, Faculty of Veterinary Medicine, Department of Microbiology, Istanbul, Turkey; e-mail: baran.celik@istanbul.edu.tr 